\title{
КЛИНИЧЕСКИЕ ХАРАКТЕРИСТИКИ ДЕБЮТА СД У ПАЦИЕНТОВ С ПЕРЕНЕСЕННОЙ COVID-19 ИНФЕКЦИЕЙ. ОПЫТ ГОРОДСКОГО СТАЦИОНАРА
}

\section{1Лазарева А.Н., ${ }^{1,2}$ Тихонович Ю.В., ${ }^{1}$ Рыбкина И.Г., ${ }^{1}$ Шрёдер Е.В., ${ }^{1}$ Гаряева И.В., ${ }^{1}$ Дагбы Ч.В.,

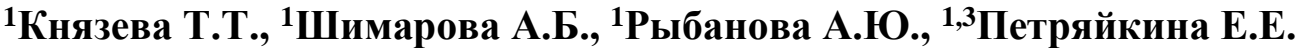

${ }^{1}$ ГБУЗ «Морозовская детская городская клиническая больница Департамента здравоохранения города Москвы», г. Москва

${ }^{2}$ ФГАОУ ВО «Первый Московский государственный медицинский университет им. И.М. Сеченова (Сеченовский университет)», г. Москва

${ }^{3}$ ФГАОУ ВО «Российский национальный исследовательский медицинский университет имени Н.И. Пирогова», г. Москва

Актуальность. Данные об особенностях течения впервые выявленного СД (СДВВ) у пациентов детского возраста с перенесенной COVID19 инфекцией ограничены отдельными сообщениями, в которых активно обсуждается роль SARS-CoV-2 как потенциального триггера ДКА.

Мы представляем клинические характеристики пациентов с впервые выявленным СД (СДВВ) и перенесенной COVID-19 инфекцией (титр IgG>10 ед), госпитализированных в Морозовскую детскую городскую клиническую больницу (МДГКБ) с марта 2020 г. по март 2021 года.

Материалы и методы. В исследование было включено 362 пациента (155 девочек и 207 мальчиков) в возрасте от 0 до 17 лет 11 месяцев 29 дней с впервые выявленным сахарным диабетом (СДВВ). Все пациентам при поступлении был определен уровень антител (IgG и IgM) к SARS-CoV-2. Титр антител IgM был отрицательный у всех пациентов. В зависимости от уровня IgG к SARS-CoV-2 (где IgG<10 ед - отрицательный титр) пациенты были разделены на 2 группы: 1 группа - 118 пациентов с перенесенной COVID19 инфекцией и 2 группа: 244 пациента с отрицательным титром IgG к SARSCoV-2.

Медиана возраста пациентов в первой группе составила 10 лет [6;12], во второй группе - 9 лет [5; 12]. ПЦР при поступлении был отрицательным во всех случаях. Клинико-лабораторное обследование пациентов проводилось в Морозовской детской городской клинической больнице (г. Москва). Статистическая обработка данных проведена в программе RStudio (Version 1.1.463 - (C) 2009-2018 RStudio, Inc.) с использованием пакета R версии 3.5.3. Сравнение групп проводили с использованием перестановочного теста (10000 итераций). Различия считали статистически значимыми при $\mathrm{p}<0.05$. Данные представлены как медианы с границами межквартильного интервала.

Результаты. Среди пациентов с СДВВ и перенесенной COVID-19 инфекцией диабетический кетоацидоз (ДКА) при поступлении отмечался в 36/118 случаев $(30,5 \%)$, из них у 50\% пациентов (18/36) - легкий ДКА, у 25\% пациентов (9/36) - средне тяжелый ДКА и у 25\% пациентов (9/36) тяжелый ДКА.

У одной пациентки отмечалось сочетание тяжелого ДКА с детским мультисистемным воспалительным синдромом (ДМВС).

Кетоз при поступлении был выявлен у 20/118 пациентов (17\%); в остальных случаях (62/118 пациентов (52,5\%)) заболевание манифестировало с гипергликемией без кетоза.

Медиана уровня гликемии при поступлении в данной группе пациентов составила 20,1 ммоль/л [14,2;24,0], медиана гликированного гемоглобина (HbA1c) - 11,5\% [10,3;12,9], медиана С-пептида $112,45[69,0 ; 155,5]$ пмоль/л, средняя суточная доза инсулина при выписке из отделения 1,04 $\pm 0,3$ ед/кг. Антитела к островковым клеткам поджелудочной железы (ICA) были определены у 88/118 человек. Положительный титр ICA был выявлен в $83 \%$ случаев, отрицательный у $17 \%$ пациентов. 
У пациентов второй группы ДКА при поступлении отмечался в 85/244 случаев (34\%), из них у 37/85 (43,5\%) пациентов - легкий ДКА, у 22/85 (26\%) пациентов - средне-тяжелый ДКА и у 26/85 (30,5\%) пациентов - тяжелый ДКА.

Кетоз при поступлении был выявлен у 64/244 пациентов (26\%); в остальных случаях (95/244 пациентов $(40 \%))$ заболевание манифестировало с гипергликемией без кетоза.

Медиана уровня гликемии при поступлении в второй группе пациентов составила 19,4 ммоль/л [14,6;26,0], медиана НbA1c -11,9\% [10,5;13,4], медиана С-пептида 108,5 пмоль/л [61,0;168,1], средняя суточная доза инсулина при выписке из отделения 1,12 $\pm 0,4$ ед/кг. Антитела ICA были определены у 182/244 человек. Положительный титр ICA был выявлен в 92\% случаев, отрицательный у 8\% пациентов.

Заключение: впервые представлены клинические характеристики дебюта СД у пациентов детского возраста с перенесенной COVID-19 инфекцией и с отрицательным титром IgG к SARS-CoV-2. Несмотря на то, статистически значимого отличия показателей углеводного обмена в представленных группах не было выявлено, возможность развития жизнеугрожающего ДМВС у пациентов с перенесенным COVID-19 требует пристального внимания к данной группе пациентов для своевременного назначения персонализированной терапии. 